ABSTRACT

UDC: 378.14.015.62

DOI: $10.26697 /$ ijes.2020.2.7

\section{Rethinking the Future of Education}

Professor Espona M. J. ${ }^{1,2,3,4}$

${ }^{1}$ Argentine Catholic University, Argentina

${ }^{2}$ National Defense University, Argentina

${ }^{3}$ University of Buenos Aires, Argentina

${ }^{4}$ Information Quality in Argentina (ArgIQ), Argentina

\section{Background:}

The past decades we witnessed a technological and communicational revolution that creates an unbalance between the curricula of most universities and what the job market requires. Because of that the offer of many short courses and professional education has grown exponentially, but the students are in most cases lost in front of the overwhelming situation.

Professors also struggle to call the attention of the students to core topics since they look meaningless in front of the fancy high tech ones.

This paper will consider some of these aspects and present an alternative solution to it.

The challenges posed by the scientific and technological evolution, as well as the communicational one (internet, mobile phones, etc.) creates a context where the traditional education is under scrutiny.

In one side of the equation we have the basic knowledge about science, essential to understand the processes and the new developments, taught in most cases in a traditional way by old school professors. It looks boring for the students because for them is difficult to see the connection. Why Isaac Newton will help them to understand astrophysics or nanophysics? Or even new materials yet to be developed? Same happens in the field of chemistry and biology.

In the other side we have the professors, struggling to keep the pace of the progress in their field to understand not only what is going on but to continue doing research and stimulating their students with attractive experiments.

What lays in between? The activities in the classroom and what is included in the syllabi.

One should reflect the other. One is formal and should follow the requirement of the Ministry of Education and the regulatory authorities and it is difficult to update. And the classroom is where the magic take place, where the professor transfers the knowledge to the students, awakes them and stimulates their curiosity.

Internet, the computers with power point, simulations, games, and other programs allows the professors to show the information in an interactive way and make it more attractive to the students.

\section{Results:}

Today we have the basic education at the university, it had changed just little over the past years. Some new degrees were added but not many.

Then, there is a proliferation of master, doctor degrees and professional education, a micro-specialization for very narrow job markets. From the university side is a big business and from the student side is a nightmare of options from where to choose.

\section{Conclusions:}

There are many alternatives, different courses, options, some more attractive or with more potential to get a job than others.

But the current academic offer is prepared for the current -highly changing-market, none is thinking in how the world will look like in 10 years, when the kids that are now starting the school will be at the university. So, the courses contents are not prepared for then but for now. They are not plastic and adaptable enough to evolve according to the circumstances.

Which is the biggest mistake? The students are not learning how to think and how to solve problems. They have a lot of information, but they do not have tools. This is what we, as professors, should, must, provide them, tools to better think and understand the world and have a critical attitude, so they will face challenges and uncertainty ready to analyze and respond in a proper way.

Information about the author:

Espona Maria Jose - Doctor in Criminology, Professor, Argentine Catholic University, National Defense University, University of Buenos Aires; Codirector, Information Quality in Argentina (ArgIQ), Buenos Aires, Argentina.

Research interests: education, chemical and biological weapons, export control of dual use goods, information quality; https://orcid.org/0000-0002-0719-0148. 